\title{
GÊNERO, PERFORMANCE ELEITORAL E PERFIS: UMA ANÁLISE DA ASSEMBLEIA LEGISLATIVA DO Paraná (1998- 2006), de Roberta Carnelos Resende ${ }^{1}$
}

\author{
Silvia Alapanian²
}

- Enviado em 04/03/2016

- Aprovado em 24/04/2016

Ao entrar em contato com os dados disponibilizados pela economista e pesquisadora Roberta Carnelos Resende através de sua dissertação de Mestrado em Sociologia, defendida em 2009 na Universidade Federal do Paraná, e intitulada "Gênero, performance eleitoral e perfis: uma análise da Assembléia Legislativa do Paraná (1998 a 2006)”, fica evidente a importância do estudo e a necessidade de aprofundamento do conhecimento acerca do processo eleitoral brasileiro.

Esse é o tema de fundo da pesquisa que busca analisar a participação das mulheres na Assembleia Legislativa do Paraná a partir de dados de uma série histórica que envolve três processos eleitorais: o de 1998, o de 2002 e o de 2006. Nela buscam-se elementos que deem indicativos da influência sobre o processo eleitoral da política de cotas de gênero instituída pela Lei 9.504 de 1997, através da qual ficou estabelecido que cada partido, ou coligação, deve reservar um mínimo de $30 \%$ e um máximo de $70 \%$ para candidaturas de cada sexo.

Numa perspectiva de defesa dos direitos humanos, a base sobre a qual se fundamenta a análise é construída a partir da convicção de que o sistema democrático erigido pela burguesia

\footnotetext{
${ }^{1}$ Dissertação de autoria de Roberta Carnelos Resende, defendida no Programa de Pós-Graduação em Sociologia da UFPR, na linha Sociedade e Estado, em 2009, sob orientação do Prof. Dr. Ricardo Costa de Oliveira. Versão completa

na Biblioteca

Digital

da

UFPR

http://dspace.c3sl.ufpr.br/dspace/bitstream/handle/1884/24875/Dissertacao_Roberta_Resende.pdf?sequence=1
}

\footnotetext{
${ }^{2}$ Professora do Curso de Serviço Social da Universidade Estadual de Londrina, Paraná, Doutora em Serviço Social e Política Social. silviaal@uel.br
} 
excluiu boa parte da população de uma participação política efetiva. Pessoas de segmentos como as mulheres, os índios, os negros e os analfabetos foram tendo reconhecidos seus direitos políticos de votar e serem votados somente a partir de décadas de luta social, sendo a inclusão desses grupos no plano político legislativo um avanço no sentido de construir processos democráticos mais participativos a partir do modelo construído de democracia representativa.

O contexto desse avanço está delineado pelo desenvolvimento do Estado de Bem Estar Social na segunda metade do século XX e pela ampliação do movimento em prol do desmembramento das normativas internacionais a partir da Declaração Universal dos Direitos Humanos, de 1948, destacando-se neste caso a Convenção sobre a Eliminação de todas as formas de Discriminação contra a Mulher (CEDAW), de 1979, à qual o Brasil aderiu somente em 1994, e que tem como objetivos a eliminação da desigualdade e a promoção, por parte dos estados signatários, da igualdade entre homens e mulheres.

As controvérsias em torno à política de cotas de gênero como mecanismo de promoção de igualdade são apresentadas ao leitor de maneira a permitir uma reflexão sobre os processos eleitorais. O exemplo da Argentina, primeiro país da América Latina a aplicar uma política de cotas de gênero, em 1991, com a qual obteve sucesso chegando à $5^{a}$ posição mundial em termos de participação política das mulheres em cargos legislativos nacionais, é bastante específico uma vez que naquele país os eleitores votam nos partidos políticos que apresentam seus candidatos em listas fechadas, com as cotas sendo asseguradas nas próprias listas: a cada três nomes, na ordem, um é de candidata mulher.

O mesmo não ocorre no Brasil e em vários outros países que adotam sistemas de cotas de gênero, uma vez que os partidos políticos criam mecanismos diversos que impedem as candidaturas de se efetivarem. No nosso caso, os partidos que não cumprem o percentual exigido não tem sofrido qualquer punição, o que acaba funcionando como um estímulo a essas estratégias.

Mesmo assim, é inegável o avanço, em nosso país, na eliminação das desigualdades a partir das conquistas das mulheres em vários setores, sendo que a pesquisadora defende que a política de cotas é também um avanço na medida em que coloca em debate a necessidade de inclusão de diversos grupos na arena política.

Porém, de forma objetiva, no Brasil o avanço da participação das mulheres no legislativo tem sido bastante lento. As mulheres brasileiras passaram a participar dos processos eleitorais a partir de 1932. Em 1933 temos a primeira mulher eleita como deputada federal para a Assembleia Nacional Constituinte. No entanto, dados disponibilizados pela pesquisadora indicam que entre as décadas de 1950 e 1970 apenas sete mulheres compuseram a Câmara Federal. 
Será a partir da Constituição Federal de 1988 que a participação das mulheres ganha maior destaque. $\mathrm{O}$ tratamento dado às mulheres na Lei consagra a sua luta pela igualdade estabelecendo uma cidadania plena, sem restrições de gênero, o que por sua vez, estimulou a participação política. Entre 1990 e 1998 foram eleitas 90 deputadas federais e 08 senadoras. Esse movimento se deu também na esfera municipal com a ampliação de 1.672 mulheres eleitas vereadoras entre 1983 e 1988, para 3.839 mulheres eleitas vereadoras entre os anos de 1993 e 1996.

Em 1995 acontece, em Pequim, a V Conferência Mundial sobre a Mulher, tendo dentre os acordos firmados entre os participantes o estabelecimento de uma Plataforma de Ação que visava o comprometimento dos países em eliminar as barreiras que impedem a plena cidadania das mulheres e, consequentemente sua ativa participação na vida pública.

O Conselho Nacional dos Direitos da Mulher, vinculado ao Ministério da Justiça, prepara, então, uma Plataforma de Ação para o país e, naquele mesmo ano a primeira lei instituindo uma política de cotas de gênero é promulgada estabelecendo que cada partido deveria destinar $20 \%$ das vagas a que tinha direito à mulheres. Criticada por possibilitar que os partidos não ocupassem todas as cadeiras a que tinham direito em caso de não eleger mulheres, essa lei foi revogada e substituída pela de n. 9.504, de 1997.

O objetivo dessas leis ao estabelecer uma política de cotas de gênero é alcançar maior presença das mulheres nos espaços públicos e, num segundo momento, maior igualdade entre homens e mulheres, o que nem sempre se dá dessa maneira. Críticos como MIGUEL (2003) apontam para a possibilidade de uma divisão do trabalho no âmbito legislativo, com as mulheres sendo responsáveis por questões relacionadas à família, à infância, aos idosos, desresponsabilizando os homens dos temas ditos "sociais", e ainda dificultando a entrada das mulheres nas discussões dos temas administrativos, econômicos e de política internacional, por exemplo.

Para alcançar a igualdade nesse campo, grupos feministas reivindicam apoio à participação das mulheres nas instâncias partidárias, estímulos e suporte às candidatas, além de subsídios à gestão das eleitas. Já estudiosos como FRASER (2002) entendem que essa igualdade passa pela alteração das condições objetivas de vida das mulheres, como o fim da dupla jornada de trabalho.

Ao pesquisar a participação das mulheres na Assembleia Legislativa do Paraná, todas essas questões estão colocadas como base para a reflexão acerca dos dados levantados. Num primeiro momento é feita uma análise comparativa da participação das mulheres em processos eleitorais de 1998 a 2006, nos estados da região sul e sudeste, a fim de situar o Paraná no contexto regional e nacional. 
A conclusão é de que o numero de candidatos, homens e mulheres, aumentou (com algumas exceções pontuais) em todo o período e em todos os estados pesquisados. A região sudeste apresentou um volume maior de candidatas do que a região sul. Ainda assim, os percentuais gerais são baixos, sendo que São Paulo e Rio de Janeiro apresentaram os maiores índices, respectivamente $13,91 \%$ e $15,15 \%$ em $1998,15,19 \%$ e $18,23 \%$ em 2002 , e $14,78 \%$ e $17,32 \%$ em 2006.

O Paraná foi o estado da região sul que apresentou, em termos absolutos, o maior numero de candidatas a deputadas estaduais nos pleitos estudados, e o segundo se o cálculo levar em consideração a relação com o numero de cadeiras disponíveis, porém, o percentual de participação feminina nas eleições foi de 10,84\% em 1998, 13,87\% em 2002 e 12,45\% em 2006.

Considerando, porém, o grau de sucesso eleitoral, isto é, o números dessas candidatas efetivamente eleitas, chegou-se a conclusão de que o Paraná é o estado que atingiu o menor percentual de mulheres eleitas dentre os sete estados estudados, com 2,22\%, o que significa dizer que para cada 100 mulheres que se candidatam somente duas conseguem se eleger no estado. Em termos concretos o Paraná elegeu 01 deputada em 1998, 04 em 2002 e 04 em 2006.

Num segundo momento, a pesquisadora propõe um exercício sociológico no sentido de incorporar o conceito de campo político de Bordieau (1998), espaço comum a um grupo de agentes, cujo interesse orienta as suas estratégias e traça o limite do próprio campo, para analisar a realidade concreta das eleições para a Assembleia Legislativa do Paraná. Quais as variáveis aumentam ou diminuem as chances de um candidato ser eleito é a pergunta.

Os dados de perfil socioeconômico de 1378 candidatos nas três eleições (1998, 2002 e 2006) recolhidos junto ao Tribunal Superior Eleitoral no Paraná, foram analisados a partir das seguintes variáveis: escolaridade, idade, profissão, estado civil, além da filiação partidária e da situação de ser candidato à reeleição.

Através do método de análise de regressão logística binária foi feita uma estimativa das chances de ocorrência ou não de um evento, primeiramente entre todos os candidatos, por processo eleitoral, e depois separadamente, para candidatos homens e mulheres.

Embora as conclusões apontem para a dificuldade desse comparativo entre vários processos eleitorais, a variável mais significativa dentre todas, com parâmetros confiáveis, é o fato de o candidato estar disputando reeleição. Isto é, segundo essas estimativas, em um processo eleitoral para deputado estadual no Paraná, estar exercendo mandato e ser candidato à reeleição aumentou em 77,1 as chances do candidato na eleição de 1998, em 36,4 em 2002 e em 51,3 em 2006. Em todos os processos eleitorais estudados a renovação das bancadas esteve próxima de 50\%, em alguns anos acima em outros pouco abaixo desse percentual. 
Os dados indicam que a passagem por um cargo eletivo na Assembleia Legislativa teve o efeito de conferir ao candidato certo crédito social, ou seja, os candidatos utilizam do recurso à credibilidade e competência de quem está exercendo a função, o que se manifesta em votos nas eleições.

Outra conclusão que vale destacar, tendo por base a análise geral, é que na variável "sexo", segundo o modelo aplicado, os dados são insignificantes, demonstrando não ter influência nas chances do candidato no processo eleitoral. Embora, quando analisadas as mesmas variáveis por grupos de candidatos homens e candidatas mulheres, separadamente, tenha-se obtido um dado que sugere que a condição de "mulher" reduza as chances de eleição, trata-se , no entanto, de dados pouco significativos em função de haver muito poucas mulheres eleitas, indicando a necessidade de novos estudos para se chegar a um indicativo minimamente seguro.

Em terceiro e ultimo momento, a pesquisadora se propõe a realizar um perfil geral dos candidatos à Assembleia Legislativa do Paraná nos três processos eleitorais já citados, utilizando-se do método de Análise de Correspondência Múltipla (ACM) que permite identificar conjuntos de características relacionadas, construindo eixos, ou dimensões, segundo as quais os candidatos se organizam por conjuntos de diferentes propriedades, finalizando com a apresentação do perfil social e da trajetória das sete candidatas eleitas no Paraná nesse período.

A construção desse perfil foi feita com os dados de escolaridade, idade, profissão, estado civil e filiação, e ainda com dados referentes a gastos com campanha, patrimônio e resultado da eleição (eleito ou não eleito). Aqui, novamente, é feito o perfil geral, seguido da apresentação de um perfil unicamente dos candidatos homens e outro das candidatas mulheres.

Os resultados são possíveis de avaliar visualmente através de gráficos que mostram quão aglutinados ou quão distantes estão os candidatos, agrupados pelas variáveis, em relação a outros, assim, é possível observar as concentrações segundo algumas dimensões. A primeira delas diz respeito à performance eleitoral dos candidatos, em que se pode separar os eleitos dos não eleitos, os "em mandato" dos "sem andado". Na segunda estão os candidatos em função da idade, separados os mais jovens dos mais velhos, e na terceira estão os candidatos de perfil socioeconômico médio a alto, de um lado, e os de perfil socioeconômico baixo, de outro. Desta forma o leitor vai observando as aglutinações das demais variáveis, proximidades e distâncias entre os vários grupos.

Vale observar que, ao realizar esse mesmo exercício utilizado o método de ACM, separadamente para o grupo de candidatos homens e de mulheres obtém-se, entre os candidatos homens praticamente o mesmo perfil geral, considerando-se que eles representam $87 \%$ do total de candidatos. O mesmo ocorre com as mulheres, devido, sobretudo, ao pequeno grupo de candidatas. 
É por esse motivo que tem sentido a apresentação do perfil das sete candidatas eleitas deputadas no período estudado, a saber, Serafina Martins Carrilho, Luciana Rafagnin, Arlete Caramês, Elza Correia, Cida Borghetti, Rosana Ferreira e Betti Pavin. Sendo os referidos perfis construídos a partir do método prosopográfico, de biografias coletivas, a partir de fontes como biografias, site da própria Assembleia Legislativa do Paraná, da Câmara Federal, além do Sistema do Monitoramento e Avaliação dos Eleitos da Federação das Indústrias do Paraná.

Todas nasceram em cidades do interior, três do Paraná, duas de Santa Catarina, uma do Rio Grande do Sul e uma de São Paulo. A maioria possui nível superior, apenas duas possuíam vínculos de parentesco com políticos e três já possuíam experiência parlamentar anterior. Significativo é ressaltar que, com uma exceção, as demais parlamentares todas possuíam fortes vínculos com movimentos de defesa de direitos das mulheres.

O interessante e desafiador trabalho de Roberta Carnelos Resende instiga à reflexão sobre o sistema de cotas de gênero, propondo um instrumento para tal que é a análise de correspondência múltipla, mas vai além, ao problematizar a questão e apresentar dados sobre as candidaturas, mesmo que num breve período que contempla três processos eleitorais, coloca a necessidade de aprofundamento dos estudos sobre os processos eleitorais em nosso país, e até mesmo sobre o sistema de democracia representativa moderno.

\section{REFERÊNCIAS}

BORDIEU, P. O poder simbólico. Rio de Janeiro, Bertrand Brasil, 1998.

FRASER, N. Políticas feministas na era do reconhecimento: uma abordagem bidimensional da justiça de gênero. In: Gênero, democracia e sociedade brasileira. Fundação Carlos Chagas, São Paulo, Editora 34, 2002.

MIGUEL, L. F. Representação política em 3 - D: Elementos para uma teoria ampliada da representação política. In: Revista Brasileira de Ciências Sociais, vol. 18, n. 51 -fev., 2003.

RESENDE, Roberta Carnelos. Gênero, performance eleitoral e perfis: uma análise da Assembléia Legislativa do Paraná (1998 a 2006). Dissertação de mestrado em Sociologia. Universidade Federal do Paraná, 2009. 109 p. 